\title{
Outcome in children from cryopreserved embryos
}

\author{
A G Sutcliffe, S w D'Souza, J Cadman, B Richards, I A McKinlay, B Lieberman
}

\begin{abstract}
A cohort of 91 children from cryopreserved embryos and 83 control children who were conceived normally had their development assessed using the Griffiths's scales of mental development. The controls (81 singletons and two twins) of a similar age, sex, and social class were selected from siblings, cousins, and peers of the cryopreserved embryo group (68 singleton, 20 twins, and three triplets). Children from cryopreserved embryos had a lower mean birth weight and mean gestational age and a higher proportion were born by caesarean section. One child from the cryopreserved embryo group had Down's syndrome, three had squints, and four had conductive hearing loss while in the control children, six had squints, and nine had conductive hearing loss. In both groups, including the child with Down's syndrome, the mean Griffiths's quotient was greater than the standard 100 . In the children from cryopreserved embryos, the singleton and multiple birth subgroups had statistically similar assessment results. The mean (SD) Griffiths's quotient was $105 \cdot 69$ (13.55) in children from cryopreserved embryos and $108 \cdot 18(9 \cdot 80)$ in controls at a chronological age of $25.08(12 \cdot 86)$ and $29 \cdot 19(14 \cdot 65)$ months respectively. Overall, the development in children from cryopreserved embryos did not cause concern though formal testing had highlighted small differences compared with other children conceived normally and of a similar social class.

(Arch Dis Child 1995; 72: 290-293)
\end{abstract}

Keywords: cryopreserved embryos, development, outcome.

Human embryos have been cryopreserved, later thawed, and transferred into women as part of an in vitro fertilisation (IVF) programme. ${ }^{1}$ This process is likely to play an increasing part in IVF with the development of superovulation regimens and advances in embryo culture and cryopreservation procedures. Cryopreservation of human embryos has certain practical advantages. Greater usage may be made of a high oocyte yield after treatment with gonadotrophin releasing hormone. As only two embryos are transferred to reduce the frequency of higher order births the remaining embryos can be cryopreserved and used subsequently in IVF. Some women after undergoing induction of ovulation develop the ovarian hyperstimulation syndrome: a condition characterised by massive ovarian enlargement and shifts in body fluids leading to ascites and hydrothorax. In such women IVF would be carried out after recovery from this condition using cryopreserved/thawed embryos. Satisfactory survival rates in human embryos have been reported after the cryopreservation/thaw process in the pronucleate stage at our IVF unit. ${ }^{2}$ A recent study which compared the birth characteristics and perinatal outcome in infants from cryopreserved embryos with those after fresh embryo transfer has shown that the mean gestational age and birth weight was not significantly different between the groups. ${ }^{3}$ There was no difference in perinatal mortality rates and the incidence of major congenital malformations was significantly lower in the cryopreserved than in the fresh embryo group.

Previous studies on obstetric outcome in IVF have reported a higher incidence of multiple pregnancies, preterm delivery caesarean section, and fetal growth retardation. ${ }^{4-6}$ There are similarities between these findings and those reported in women after transfer of cryopreserved human embryos. ${ }^{7}$

In the present study we have followed up a group of children from cryopreserved embryos and compared their developmental outcome with that of children conceived normally.

\section{Patients and methods}

One of us (AGS) followed up in an outpatient clinic 91 children conceived from cryopreserved embryos in the IVF unit at St Mary's Hospital, Manchester, or Manchester Fertility Services Ltd, and born between 27 December 1989 and 18 January 1994. The control group of 83 children, who had been conceived normally, were also seen at these clinics. They were matched for social class (according to father's occupation, using data from the Office of Population Censuses and Surveys ${ }^{8}$ ) and age. These children were either siblings, cousins, or peers of the study group. It was not possible for the controls to be matched for multiplicity of births (twins or triplets), this being inevitably difficult as the IVF children tend to be a group with a much higher frequency of multiple births. A match for geographical area was 
Table 1 Cryopreserved embryo and control infants; results are number of infants except where stated otherwise

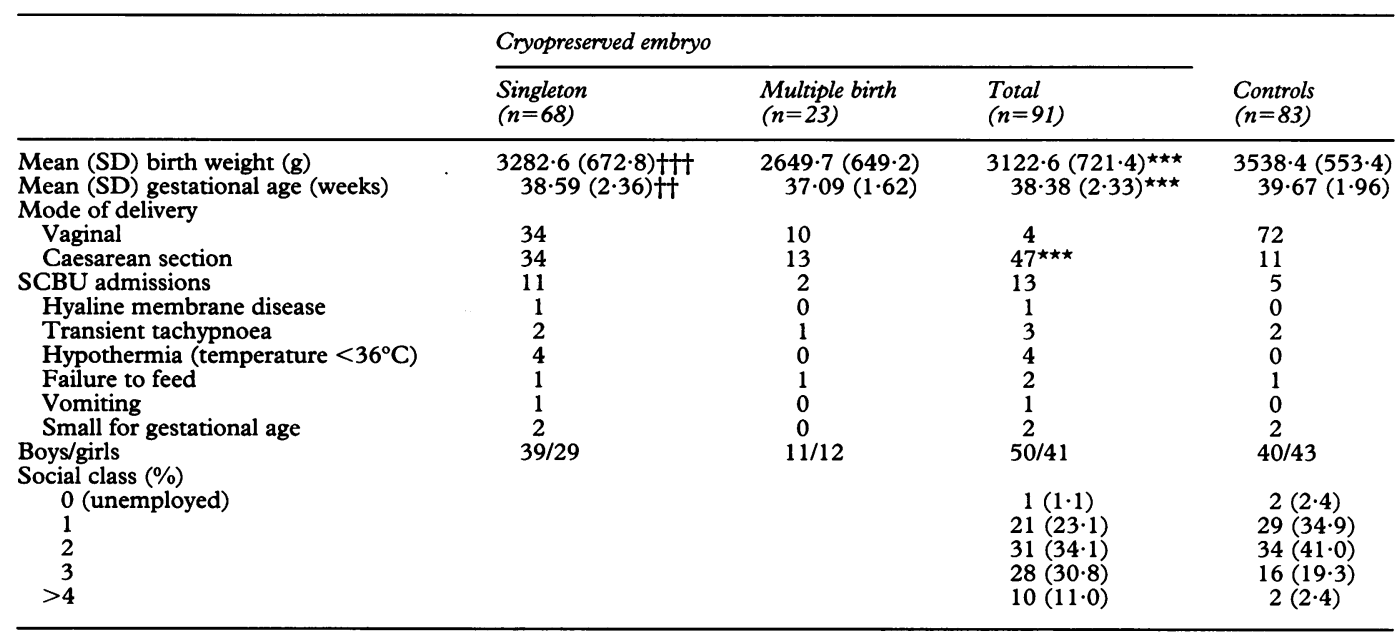

Levels of significance: total (cryopreserved embryo) $v$ controls, ${ }^{\star \star \star} \mathrm{p}<0.001$; singleton (cryopreserved embryo) $v$ multiple births (cryopreserved embryo), $t+\mathrm{t}<0.001, t+p<0.01$. SCBU $=$ special care baby unit.

attained; all children in both groups having been born in the North West region of England have continued to live in this area. The assessments at outpatient clinics included a general medical examination and a developmental assessment using the Griffiths's scales of mental development. ${ }^{910}$ When a squint or hearing loss was suspected the clinical finding was confirmed by referring the child to a specialist ophthalmology or audiology clinic. The study was completed in the 12 months between August 1993 and September 1994.

\section{STATISTICS}

Mean values were compared using Student's $t$ test. The $\chi^{2}$ test was used for comparing proportions in comparing the cryopreserved embryo group with those in controls.

\section{Results}

In the cryopreserved embryo group $(n=91)$ there were 68 singletons and the remaining 23 children were from multiple births including 20 twin and three triplet children. The controls $(n=83)$ consisted of 81 singleton and two twin children. The demographic data in these two groups of children are shown in table 1. The cryopreserved embryo group of children (total) had a lower birth weight and a lower gestational age because of a higher proportion of preterm births. In the cryopreserved embryo group $10(12 \cdot 7 \%)$ of 79 births were preterm $(<37$ weeks gestational age) compared with six $(7 \cdot 3 \%)$ of 82 births in the control group $(p<0.01)$. There was a higher proportion of preterm births from multiple pregnancies, three $(27 \cdot 3 \%)$ of 11 compared with seven $(10 \cdot 3 \%)$ of 68 singleton

Table 2 Clinical assessment

\begin{tabular}{llllll}
\hline & \multicolumn{2}{l}{ Cryopreserved } & & \\
\cline { 2 - 5 } & $\begin{array}{l}\text { Singleton } \\
(n=68)\end{array}$ & $\begin{array}{l}\text { Multiple birth } \\
(n=23)\end{array}$ & $\begin{array}{l}\text { Total } \\
(n=91)\end{array}$ & $\begin{array}{l}\text { Controls } \\
(n=83)\end{array}$ \\
\hline Squints & 3 & 0 & 3 & 6 \\
Conductive hearing loss & 4 & 0 & 4 & 9 \\
Down's syndrome & 1 & 0 & 1 & 0 \\
\hline
\end{tabular}

pregnancies from cryopreserved embryos $(p<0.01)$. A comparison of the proportion of children born by caesarean section and vaginal delivery showed that a higher proportion of the former were from the cryopreserved embryo group compared with controls $(52 \% v 13 \%$, table 1$)$.

\section{CLINICAL ASSESSMENT}

Neurological conditions found on clinical examination included squints and conductive hearing loss (table 2). There was one child with Down's syndrome in the cryopreserved embryo group. This child was not excluded from further assessment.

GRIFFITHS'S SCALES OF MENTAL DEVELOPMENT The two groups were assessed at a similar chronological age which was not corrected for preterm birth (table 3 ). The mean mental age was higher (by 5.29 months) in the control group compared with the cryopreserved embryo group, and there was an associated increase in the mean Griffiths's quotient that did not reach statistical significance. With respect to the subquotients for locomotor, personal-social, hearing and speech, eyehand coordination, and performance the only significant difference was in hearing and speech (table 3 ). In the cryopreserved embryo group the Griffiths's quotient and the subquotients were compared in children from the singleton and the multiple birth subgroups but none was statistically significant. The mean mental age in these subgroups was statistically similar.

\section{Discussion}

In the present study there were limitations in our choice of control children. Although we are aware that women who achieve pregnancy by IVF are usually older than average parents, their infertility might indicate genetic and other medical disorders and they have a higher incidence of multiple pregnancy, caesarean section, and preterm births. ${ }^{4-6} \mathrm{We}$ found that 
Table 3 Griffiths's scales of mental development; results are mean (SD)

\begin{tabular}{|c|c|c|c|c|}
\hline & \multicolumn{3}{|c|}{ Cryopreserved embryo } & \multirow[b]{2}{*}{$\begin{array}{l}\text { Controls } \\
(n=83)\end{array}$} \\
\hline & $\begin{array}{l}\text { Singleton } \\
(n=68)\end{array}$ & $\begin{array}{l}\text { Multiple birth } \\
(n=23)\end{array}$ & $\begin{array}{l}\text { Total } \\
(n=91)\end{array}$ & \\
\hline Chronological age (months) & $24 \cdot 39(12 \cdot 13)$ & $27 \cdot 15(14 \cdot 61)$ & $25 \cdot 08(12 \cdot 86)$ & $29 \cdot 19(14 \cdot 65)$ \\
\hline Griffiths's quotient & $105.04(14.47)$ & $107 \cdot 61(10 \cdot 12)$ & $105.69(13.55)$ & $108 \cdot 18(9 \cdot 80)$ \\
\hline Mental age (months) & $25.97(14 \cdot 21)$ & $29.13(16.57)$ & $26.77(14.91)$ & $32.06(17.09)^{\star}$ \\
\hline \multicolumn{5}{|l|}{ Subquotients } \\
\hline Locomotor & $104 \cdot 54(17 \cdot 95)$ & $108.52(13.05)$ & $105.55(16.93)$ & $104 \cdot 10(11 \cdot 73)$ \\
\hline Personal-social & $108 \cdot 78(17.91)$ & $111.00(10 \cdot 76)$ & $109 \cdot 34(16 \cdot 43)$ & $109 \cdot 18(12 \cdot 12)$ \\
\hline Hearing and speech & $106 \cdot 18(21 \cdot 24)$ & $108.04(13.14)$ & $106.65(19.53)$ & $112.33(13.87)^{\star}$ \\
\hline Eye-hand coordination & $100 \cdot 85(14 \cdot 53)$ & $105 \cdot 26(9 \cdot 46)$ & $101.97(13.56)$ & $106 \cdot 20(15 \cdot 11)$ \\
\hline Performance & $105.01(16.68)$ & $106.96(12 \cdot 50)$ & $105.51(15.75)$ & $108 \cdot 40(15 \cdot 32)$ \\
\hline
\end{tabular}

Cryopreserved embryo (total) $v$ controls, ${ }^{\star}<0 \cdot 05$.

it was not possible to identify control children matched by parental age, parity, multiplicity of pregnancy, history of infertility, mode of delivery, and preterm birth. As these conditions may be predictive of increased obstetric risks and adverse outcomes in later childhood we realised from the outset that it would be difficult drawing firm conclusions because our control children were only matched for social class, sex, and age (table 1 ).

We found that most children from cryopreserved embryos did not have a neurological abnormality at follow up. Despite a higher incidence of preterm births and a lower mean birth weight in the cryopreserved embryo group none of these children had major disabilities such as cerebral palsy, sensorineural deafness, impaired vision, or developmental delay, which have been previously reported in low birthweight children from a geographically defined population. ${ }^{11}$ Squints and conductive deafness have previously been reported in low birthweight children ${ }^{12}$ and squints have been reported in children conceived by IVF. ${ }^{13}$ In the present study, the frequency of squints and conductive hearing loss was similar in the cryopreserved embryo group and in controls. It would seem unlikely, therefore, that the procedures used in cryopreservation or thawing embryos had predisposed to the development of squints or conductive hearing loss.

Down's syndrome and other chromosomal abnormalities have been reported in a survey of births resulting from IVF. ${ }^{5}$ The proportion of births from transfer of cryopreserved embryos in this survey was not clearly specified. Rizk et al reported Edward's syndrome (trisomy 18) in a fetus from a cryopreserved embryo. ${ }^{14}$ This fetus, like the child in our study with Down's syndrome (trisomy 21), had developed from an embryo that was cryopreserved in the pronucleate stage. The idea that there may be a link between the cryopreservation process and chromosomal abnormalities remained unsubstantiated when the outcome in cryopreserved embryo transfer was compared with that after fresh embryo transfer. ${ }^{3}$ There was no chromosomal abnormality reported in 283 infants conceived after transfer of cryopreserved embryos, but chromosomal abnormalities were observed in five of 961 infants after transfer of fresh embryos. The process of cryopreservation therefore may not increase the risk of chromosomal abnormalities in liveborn infants but we do not know whether this is because some embryos are lost in the cryopreservation/thaw process or early fetal losses occur due to abnormal chromosomes.

Previous studies on the development of children conceived by IVF have shown no evidence of developmental delay. ${ }^{15-18} \mathrm{We}$ have obtained comparable results in children from cryopreserved embryos, after including the child with Down's syndrome. The mean Griffiths's quotient in the cryopreserved embryo group and in controls was above the standard 100 . It may be that the family background in our two groups of children had similarities which placed them at an advantage with regard to development.

Nevertheless, the mode of conception had significantly affected mean mental age in children from cryopreserved embryos due to a small reduction in the Griffiths's quotient compared with controls. The controls were four months older than the subjects. In these circumstances, therefore, the statistically significant differences between the mental age and in the hearing and speech subquotient are of no practical importance. It is noteworthy that, in the cryopreserved embryo group, children from multiple births and singleton birth showed a comparable performance for a range of subquotients; as a consequence their mean Griffiths's quotient and their mean mental age were statistically similar (table 3 ). By contrast, in a previous study in children conceived by IVF (largely fresh embryo transfer), twin and triplet children performed less well than singletons when tested at a similar chronological age using the Griffiths's scales of mental development. ${ }^{17}$

Cryopreservation in human embryos may confer considerable benefits by increasing the numbers of pregnancies in an IVF programme. Our results of follow up in these infants are reassuring apart from the one child with Down's syndrome. Conductive hearing loss should resolve with appropriate management. These children from cryopreserved embryos should enter mainstream schooling and we envisage that they are likely to perform as well as other children conceived normally and of a similar social class background.

The grant received from the Association for Research in Infant and Child Development is gratefully acknowledged. We thank the parents and children who took part in this study and Mrs Elaine Evans and Mrs Rita Scott for secretarial assistance.

1 Trounson AO, Mohr L. Human pregnancy following cryopreservation thawing and transfer of an eight-cell embryo. Nature 1983; 305: 707-9.

2 Troup SA, Matson PL, Critchlow JD, Moroll DR, Lieberman BA, Burslem RW. Cryopreservation of human 
embryos at the pronucleate, early cleavage or expanded blastocyst stages. Eur f Obstet Gynecol Reprod Biol 1990; 38: 133-9.

3 Wada I, Macnamee MC, Wick K, Bradfield JW, Brinsden PR. Birth characteristics and perinatal outcome of babies conceived from cryopreserved embryos. Hum Reprod 1994; 9: 543-6.

4 Australian In Vitro Fertilisation Collaborative Group. High incidence of preterm births and early losses in pregnancy after in

5 MRC Working Party on Children Conceived by In Vitro Fertilisation. Births in Great Britain resulting from assisted conception, 1978-87. BMF 1990; 300: 1229-33.

6 Tan S-L, Doyle P, Campbell S, et al. Obstetric outcome of in vitro fertilization pregnancies compared with normally conceived pregnancies. Am $\mathcal{F}$ Obstet Gynecol 1992; 167 : 778-84.

7 Frydman R, Forman RG, Belaisch-Allart J, Hazout A, Fernandez H, Testart J. An obstetric analysis of fifty consecutive pregnancies after transfer of cryopreserved human embryos. Am f Obst Gynecol 1989; 160: 209-13.

8 Office of Population Censuses and Surveys. Classification of occupations. London: HMSO, 1970.

9 Griffiths R. The abilities of babies: a study in mental measurement. London: London University Press, 1954

10 Griffiths R. The abilities of babies: a study in mental measurement. Norfolk: Lowe and Brydone, 1976.

11 The Scottish Low Birthweight Study Group. The Scottish low birthweight study: 1. Survival, growth, neuromotor and sensory impairment. Arch Dis Child 1992; 67: 675-81.

12 Marlow N, D'Souza SW, Chiswick MI Neurodevelopmental outcome in babies weighing less than $2001 \mathrm{~g}$ at mental outcome in babies weighing less than $2001 \mathrm{~g}$ at

13 D'Souza SW, Rivlin E, Buck P, Lieberman BA. Children conceived by in vitro fertilization. In: Matson PL, Lieberman BA, eds. Clinical IVF forum: current views in assisted reproduction. Manchester: Manchester University Press, 1990: 70-8.

14 Rizk B, Edwards RG, Nicolini U, Meagher S, Lamon RF Edward's syndrome after the replacement of cryopreserved-thawed embryos. Fertil Steril 1991; 55: 208-10.

15 Yovich JL, Parry TS, French NP, Grauang AA Developmental assessment of twenty in vitro fertilization (IVF) infants at their first birthday. Fournal of In Vitro Fertilisation and Embryo Transfer 1986; 3: 253-7.

16 Morin NC, Wirth FH, Johnson DH, et al. Congenital malformations and psychosocial development in children conceived by in vitro fertilization. 7 Pediatr 1989; 115: 222-7.

17 D'Souza SW, Rivlin E, Buck P, Lieberman BA. Altered sex ratios. Lancet 1989; ii: 689-90.

18 Berendes JM, Scher A, Itzkovits J, Thaler I, Sarid M, Gershoni-Baruch R. Growth and development of children conceived by in vitro fertilization. Pediatrics 1992; 90: 424-9. 